\title{
Data Driven Disturbance Observer Design and Control for Diesel Engine Airpath
}

\author{
Volkan Aran and Mustafa Unel*
}

\begin{abstract}
Diesel engine airpath is a popular nonlinear control plant in the literature. Airpath is one of the key elements for engine out emissions control of the diesel engines. Its robust control requires controller design based on a nonlinear model of a system. Analytical model based control approaches are common in the literature. This study presents discrete sliding mode control and data driven disturbance observer design for diesel engine airpath. Identification tests and controller performance are simulated in a modeling environment where disturbance rejection capability of the developed control system is also characterized.
\end{abstract}

\section{INTRODUCTION}

Developing emission regulations of the diesel engines created the need for better engine out emission control. Diesel engine emission control can be examined under two titles: airpath and Fuel path. airpath control consists of mainly regulating following three actuators: throttle valve, exhaust gas recirculation (EGR) valve and variable geometry turbine (VGT) vane or waste gate. Transient control of diesel engine airpath is focused on transient emissions and torque build up. One of the most important exhaust emission gases is Nitrous Oxide. EGR system is the major NOx reduction system for engine out emissions [1].

Emerging electrical engine and battery technologies are challenging the diesel engine. Hybridization and aftertreatment technologies require different actuators and system layouts. Thus, any control structure should be flexible to these upcoming physical hardware changes. Also, commercial vehicles require around 1 million kilometers service life. Serial production of hundreds of parts creates a variability from engine to engine. Robustness to the part variances and aging of the components is required for mobile vehicle applications. These concerns define general overview of the problem and airpath control system should be flexible to the hardware changes and robust to the part to part variance and aging to some extend. A flexible and robust control system is being sought for heavy duty diesel engine airpath problem.

PI(D) based industrial control algorithms are common. With the variations in the application, PID control is one of the standard methods in the airpath control literature ([2], [3], [4], [5]) besides increasingly popular model predictive control ([6], [7], [8], [9], [10], [11], [12]). Other control

\footnotetext{
*Corresponding Author

Volkan Aran is with both Ford Otosan Product Development and Faculty of Engineering and Natural Sciences, Sabanci University, Istanbul, Turkey varan 4 eford. com

Mustafa Unel is with Faculty of Engineering and Natural Sciences, Sabanci University, Istanbul, Turkey munel d sabanciuniv.edu
}

methods such as sliding mode control ([13], [14], [15], [16]) , $H_{\infty}$ control ([17]), LQG-LTR [18], Adaptive Control [19] and Control Lyapunov Functions [20] are also found in the airpath control literature.

To increase robustness against external disturbances, an extended state observer approach is presented in [16] for diesel engine airpath where the state is augmented with the disturbance. States estimated with this physical model based extended state observer are utilized in the design of the super twisting sliding mode control. Although disturbance observer has various successful applications [21], finding and inverse nominal model may not be a straightforward process. Airpath control literature is dominated by model based control approaches. Application of data-driven techniques such as Virtual Reference Feedback Tuning (VRFT)[5] does also exist. This novel method aims to identify controller parameters (i.e. PI gains) directly from a training data whose contributions were designing an optimum prefilter on data and extended instrumental variables with variance weighting. In order to validate the proposed strategy of MIMO VRFT method, diesel engine airpath control problem of mass airflow (MAF) and intake manifold pressure (MAP) tracking is considered as the case. Excitation of valve position with pseudo random binary sequence (PRBS) waveform signals are used for identification of the system.

Due to the changes in the physical system characteristics with time and presence of the disturbances (i.e. engine speed changes, leakages, actuator nonlinearities), airpath control requires a robust control approach. Disturbance observer and sliding mode control are two important tools for dealing with the uncertainities and external effects.

This study proposes a novel disturbance observer (DOB) design based on system identification for MAF control via EGR valve. Due to complexity of the physical model and its uncertainities, a data driven disturbance observer approach is cruical. Data driven control is an emerging field [22] and finds its applications in diesel engine airpath as well [5]. Airpath system is inherently a nonminimum phase system and nominal inverse plant can not be obtained directly. In the presented study, a finite impulse response (FIR) model for nominal inverse plant based on a nonlinear system identification method is utilized to resolve the inversion issue. In the outer loop, the discrete time sliding mode control (DTSMC) approach proposed in[23] is employed. Both identification and control implementations are demonstrated on a high fidelity nonlinear engine model detailed in [24].

In this paper, system identification for EGR line (i.e. 
data based modeling for EGR valve to mass airflow dynamics) will be explained after introduction. Controller and disturbance observer development based on discrete sliding mode and nonlinear identification models will be presented in the third part and simulation results with disturbances will be presented in the results section. Conclusions and future studies will be discussed in the last section.

\section{SyStem IDENTIFICATION FOR EGR}

Control of the air variables is a part of the whole engine control problem. Overall aim of the powertrain management is providing desired speed (via creating the desired torque) to the vehicle and satisfying tail pipe emission limits. The engine output power and emissions control is achieved via manipulation of fuel variables (i.e. fuel injection (rail) pressure, fuel injection quantity, fuel injection timing) and air variables (intake manifold pressure, MAP and (fresh) mass air flow, MAF). Desired MAF and desired MAP values are generally interpolated from tables which has speed and inner torque axes. Exhaust manifold pressure, exhaust manifold temperature, turbocharger speed and intake manifold pressure values are fedback to the controllers and they are available via modeling or sensors based on engine layout. General trend is using MAF and MAP sensors and modeling the remaining parameters. Overall signal flow can seen from Fig. 1.

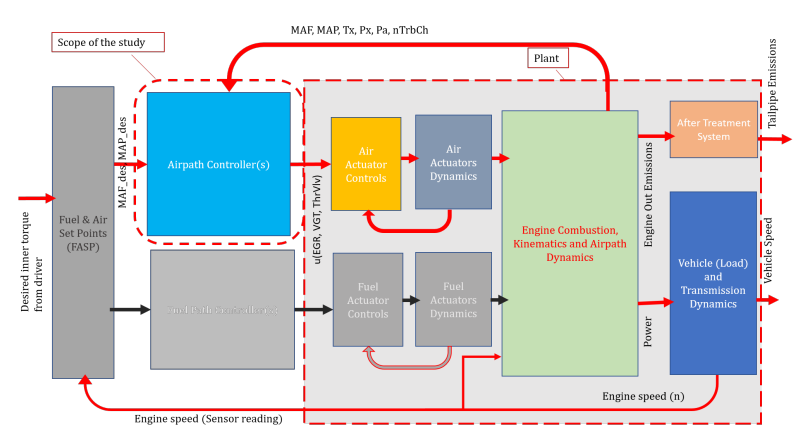

Fig. 1. Diesel Engine Control Diagram

A simplified yet useful third order modeling approach of the airpath is based on ideal gas law and a time constant for turbine to compressor power transfer dynamics. The model state equations are presented in the Eq. 1-3. This nonlinear control formulation for the airpath control problem with two actuators (i.e. EGR Valve, VGT vanes) is proposed for airpath control [20] and used by other robust controller designs in the literature [25] [16]. System is defined by three states, namely, intake manifold pressure $P_{i}$, exhaust manifold pressure $P_{x}$, compressor power $P_{c}$. These are formulated with respect to the related parameters: Compressor air mass flow $W_{c i}$, exhaust gas recirculation mass flow $W_{x i}$, total air mass flow in the intake manifold of the engine $W_{i e}$, fuel mass flow $W_{f}$, compressor power $P_{c}$, turbine power $P_{t}$. The outputs are selected as $W_{c i}$ and $P_{i}$. Constant temperatures are assumed by [20], (i.e. $\dot{T}_{x}=0, \dot{T}_{i}=0$ ) for further simplicity and assuming engine operation temperature variation is limited. This could be a weak assumption for exhaust temperatures but it is reasonable for intake manifold temperatures. In the mentioned study, limited operation area justified the assumption. Compressor power is calculated from isentropic work and multiplication with a isentropic efficiency parameter $\eta_{c}$. EGR flow ( $W_{x i}$ is calculated via throttle equation on EGR valve. The total gas flow into the engine is calculated with ideal gas law and a volumetric efficiency multiplication. Intake manifold gas states are taken as reference to the volumetric efficiency. Here the ideal gas constant $R$, intake manifold temperature $T_{i}$, intake manifold volume $V_{i}$, coefficient of heat of the air $c_{p}$, ambient temperature $T_{a}$, specific heat ratio $\mu$, volumetric efficiency $\mu_{v}$, engine displacement volume $V_{d}$, engine speed $N$, EGR valve area $A r_{E G R}$, turbine inlet area $A r_{V G T}$, reference temperature for turbine model $T_{R e f}$, turbine model coefficients $a, b, c, d$ are used. Control variables are $u=\left(A r_{E G R}, A r_{V G T}, A r_{T H R}\right)$. The state equations for $P_{i}$ is given in (1), exhaust manifold pressure $P_{x}$ is in (2) and compressor power $P_{c}$ is shown in (3). The output equation for the air mass flow $W_{c i}$ is presented in (4).

$$
\begin{gathered}
\dot{P}_{i}=\frac{R T_{i}}{V_{i}} \frac{\eta_{c}}{c_{p} T_{a}} \frac{P_{c}}{\left(\frac{P_{i o}}{P_{a}}\right)^{\mu}-1}-\frac{P_{i}}{V_{i}} \frac{\eta_{v}}{2} \frac{V_{d}}{60} N \\
+\frac{R T_{i}}{V_{i}} \frac{P_{x}}{\sqrt{R T_{x}}} \sqrt{2 \frac{P_{i}}{P_{x}}\left(1-\frac{P_{i}}{P_{x}}\right) A r_{E G R}}
\end{gathered}
$$

$$
\begin{aligned}
& \dot{P}_{x}=\frac{T_{x}}{T_{i}} \frac{P_{i}}{V_{x}} \frac{\eta_{v}}{2} \frac{V_{d}}{60} N+\frac{R T_{x}}{V_{x}} W_{f}-\frac{R T_{x}}{V_{x}} \frac{P_{x}}{\sqrt{R T_{x}}} \times \\
& \times \sqrt{2 \frac{P_{i}}{P_{x}}\left(1-\frac{P_{i}}{P_{x}}\right) A r_{E G R}-\frac{R T_{x}}{V_{x}} a\left(c\left(\frac{P_{x}}{P_{a}}-1\right)+d\right) \times} \\
& \times \frac{P_{x}}{P_{r e f}} \sqrt{2 \frac{P_{a}}{P_{x}}\left(1-\frac{P_{a}}{P_{x}}\right)} \sqrt{\frac{T_{R e f}}{T_{x}}} A r_{V G T} \\
& -\frac{R T_{x}}{V_{x}} b\left(c\left(\frac{P_{x}}{P_{a}}-1\right)+d\right) \frac{P_{x}}{P_{\text {Ref }}} \sqrt{2 \frac{P_{a}}{P_{x}}\left(1-\frac{P_{a}}{P_{x}}\right)} \sqrt{\frac{T_{R e f}}{T_{x}}}
\end{aligned}
$$

$$
\begin{gathered}
\dot{P}_{c}=-\frac{P_{c}}{\tau}+\frac{\eta_{t} c_{p} T_{x}}{\tau}\left(\sqrt{2 \frac{P_{a}}{P_{x}}}\left(1-\frac{P_{a}}{P_{x}}\right) A r_{V G T} \times\right. \\
\times\left(\left(1-\left(\frac{P_{a}}{P_{x}}\right)^{\mu}\right) \frac{P_{x}}{P_{R e f}} \sqrt{\frac{T_{R e f}}{T_{x}}} a\left(c\left(\frac{P_{x}}{P_{a}}-1\right)+d\right)\right. \\
+\left(1-\left(\frac{P_{a}}{P_{x}}\right)^{\mu}\right) \frac{P_{x}}{P_{R e f}} \sqrt{\frac{T_{R e f}}{T_{x}}} b\left(c\left(\frac{P_{x}}{P_{a}}-1\right)+d\right) \times \\
\times \sqrt{\left.2 \frac{P_{a}}{P_{x}}\left(1-\frac{P_{a}}{P_{x}}\right)\right)} \\
W_{c i}=\frac{\eta_{c}}{c_{p} T_{a}} \frac{P_{c}}{\left(\frac{P_{i o}}{P_{a}}\right)^{\mu}-1}
\end{gathered}
$$

In the presented equations control inputs are shown as effective valve areas. Valve area to position relation is dependent to the valve geometry and discharge coefficient of the valve. Finding exact effective areas requires 3D flow analysis on the valve section and that is another nonlinear relation[26]. This complex relations favors using data based 
approach for plant modeling. For a given fuel air setpoints set, overall system inputs are speed and accelerator pedal position as discussed before. For these two inputs chirp signal based experiment is designed with the method shown in [27]. For validation test World Harmonized Transient Cycle (WHTC) is used. Both tests are run in the engine model.

Airpath plant is known to be a nonminimum phase system [28] due to the delays between boost build up and exhaust manifold pressure rise (i.e. enegry transfer between compressor and turbine via engine). Model inputs are intake manifold pressure $P_{i}$, exhaust manifold pressure $P_{x}$, compressor power $P_{c}$ and EGR valve position $E G R_{p o s}$. MATLAB system identification toolbox is used for generation of the models [29]. Transfer function between EGR valve and MAF has zeros in the right half plane as can be seen from the (5). Higher orders identification models exhibits the same behaviour as well. Transfer functions obtained from the identificaiton process are as follows:

$$
\begin{aligned}
& \frac{W_{c i}(s)}{E G R_{\text {pos }}(s)}=\frac{-112.1 s^{2}+7.954 s-18.12}{s^{3}+25.58 s^{2}+30.54 s+9.532} \\
& \frac{W_{c i}(s)}{P_{i}(s)}=\frac{-0.4257 s^{2}+0.05209 s+0.3657}{s^{3}+3.956 s^{2}+5.248 s+2.516} \\
& \frac{W_{c i}(s)}{P_{x}(s)}=\frac{7.651 s^{2}+6.512 s-3.781}{s^{3}+2 s^{3}+26.98 s^{2}+62.56 s+33.94} \\
& \frac{W_{c i}(s)}{P_{c}(s)}=\frac{0.05235 s^{2}+0.0661 s+0.02747}{s^{3}+3.618 s^{2}+4.413 s+1.793}
\end{aligned}
$$

Since the physical system model is a nonlinear one, one can identify the plant behaviour with a Nonlinear Auto Regressive with eXogenous variable (NARX) model. The inputs-output scheme used for identification is depicted in Fig. 2. For the specific model used in the study, all inputs

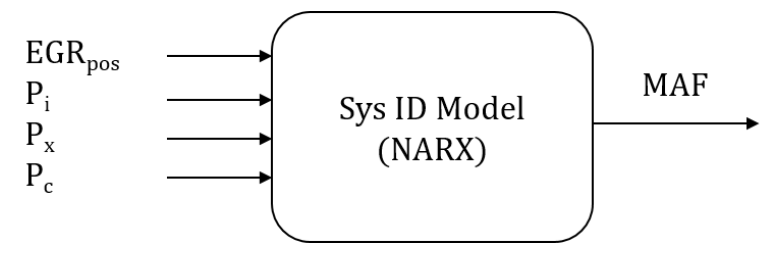

Fig. 2. EGR Model inputs and output

have 5 past values and no output term is added to regressors for both linear and nonlinear part. 5 sigmoid units are used for modeling nonlinear dynamics. Model training best fit value is $82 \%$ and validation on the WHTC cycle is the $70 \%$ as shown in Fig. 3. Resulting model details and related controller synthesis will be further explained in the next section.

\section{Disturbance ObSERVER AND CONTROLler}

In order to overcome disturbance effects on a system, DOB is proposed by Ohnishi et. al. [30]. In the classic DOB control structure, estimated disturbances are fedback to the control loop as shown in Fig.4. A DOB implementation requires two steps: Defining nominal inverse model parameters $\left(G_{n}^{-1}\right)$ and
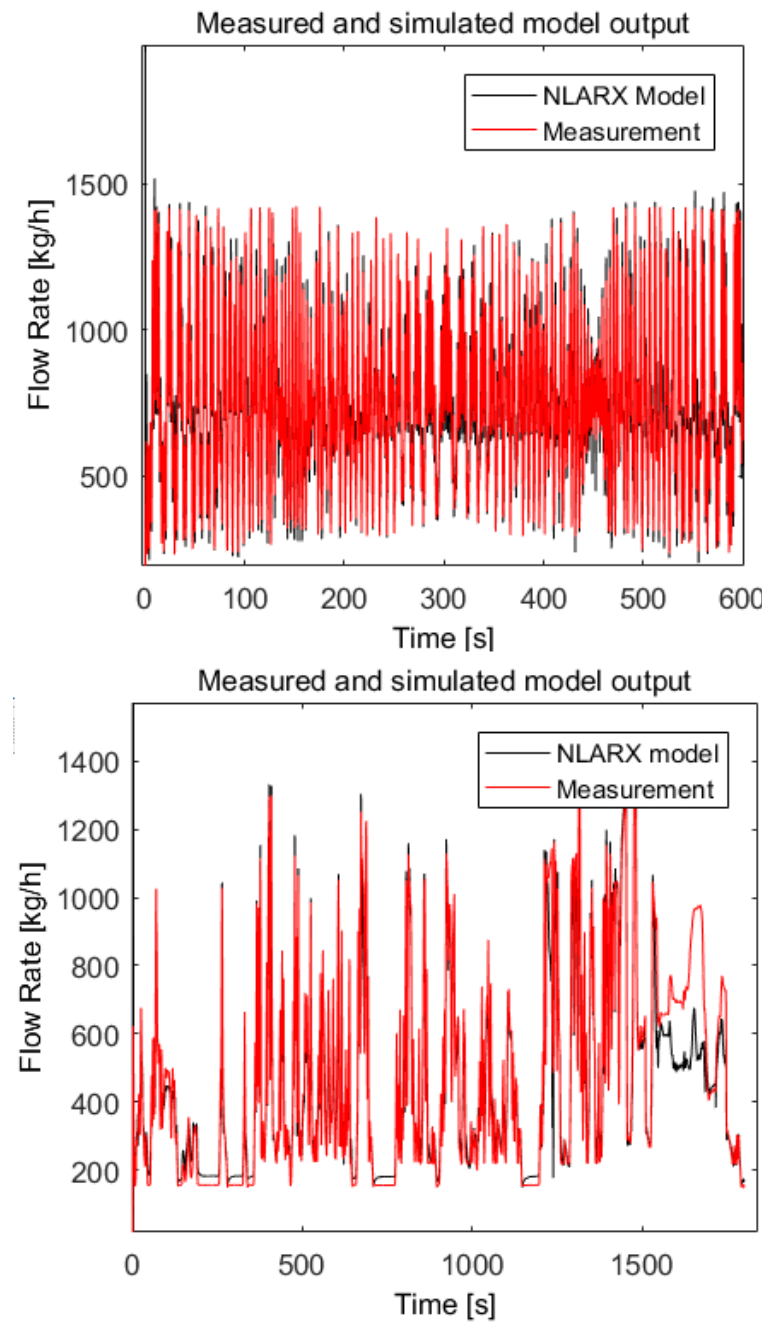

Fig. 3. Training (Top) and Validation (Bottom) Results

filter parameters $(Q)$. Nominal inverse plant is obtainable when plant has minimum phase behaviour in the classic approach. A modified disturbance observer is proposed with estimated delay and prefilter scheme in [31]. Our approach has inherently stable finite impulse response (FIR) type linear model by design. The other nonlinearities are moved to the disturbance as shown in Fig.5. Original NLARX structure is interpreted as linear FIR model (by excluding output regressors) in addition to nonlinearities and disturbances. In the previous section, model was selected to be a NARX for system output, which have the form of (6) [32] where $L$ is $n \times n$ coefficient matrix and $P$ is $1 \times n$ coefficient vector. Nonlinear part is a sigmoid function, essentially one layer sigmoid network. NARX linear part has an input mean parameter $r$ and an offset parameter $d$ : i.e.

$$
\begin{aligned}
& y=(x-r) P L+d+\sum\left(a_{i} e^{1+(x-r) Q b_{i}+c_{i}}\right) \\
& =L_{n} x-L_{n} r+d+\sum\left(a_{i} e^{1+(x-r) Q b_{i}+c_{i}}\right)
\end{aligned}
$$




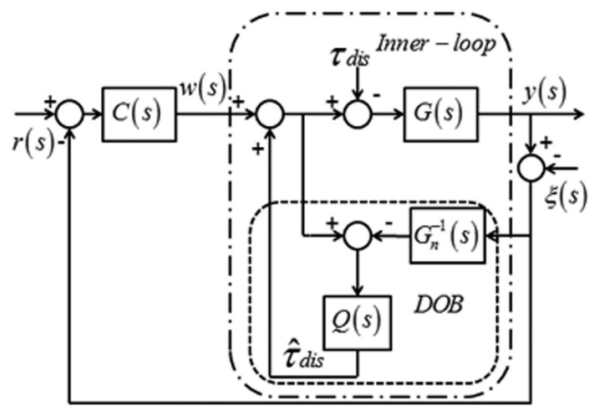

Fig. 4. Block diagram for DOB integrated system [33]

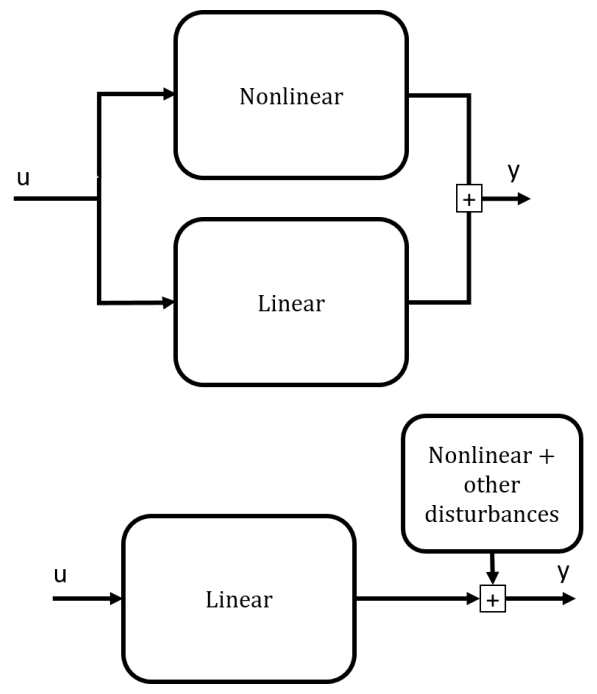

Fig. 5. Block diagram for classic NLARX structure and linear nominal plant and disturbance interpretations based on NLARX

where $L_{n} \triangleq P L$. In order to compute the output of the nominal inverse plant, we can utilize the linear part in (6) along with the MAF output and inputs $E G R_{\text {position }}$, intake manifold pressure $\left(P_{i}\right)$, exhaust manifold pressure $\left(P_{x}\right)$ and compressor power $\left(P_{c}\right)$ as in (7).

$$
\begin{aligned}
& M A F=L_{n} x \\
& \Rightarrow M A F(t)=a_{1} E G R_{\text {pos }}(t-1)+\ldots+a_{n a_{1}} E G R_{\text {pos }}\left(t-n a_{1}\right) \\
& +b_{1} P_{i}(t-1)+b_{2} P_{i}(t-2)+\ldots+b_{n a_{2}} P_{i}\left(t-n a_{2}\right) \\
& +c_{1} P_{x}(t-1)+c_{2} P_{x}(t-2)+\ldots+c_{n a_{3}} P_{x}\left(t-n a_{3}\right) \\
& +d_{1} P_{c}(t-1)+d_{2} P_{c}(t-2)+\ldots+d_{n a_{4}} P_{c}\left(t-n a_{4}\right)
\end{aligned}
$$

In order to overcome the causality problem of inverse model, a first order low-pass filter is utilized as in Fig. 4. In light of (7), EGR position can be determined from low-pass filtered MAF as

$$
\begin{aligned}
& E G R_{\text {pos }}(t-1)=\left[-M A F(t-1) \ldots+a_{n a_{1}} E G R_{p o s}\left(t-n a_{1}-1\right)\right. \\
& +b_{1} P_{i}(t-1)+b_{2} P_{i}(t-2)+\ldots+b_{n a_{2}} P_{i}\left(t-n a_{2}\right) \\
& +c_{1} P_{x}(t-1)+c_{2} P_{x}(t-2)+\ldots+c_{n a_{3}} P_{x}\left(t-n a_{3}\right) \\
& \left.+d_{1} P_{c}(t-1)+d_{2} P_{c}(t-2)+\ldots+d_{n a_{4}} P_{c}\left(t-n a_{4}\right)\right] / a_{1}
\end{aligned}
$$

For a plant in control affine form (9), outer loop control can be realized with the discrete time sliding mode controller (DTSMC) [23] given by (10) where the sliding surface is defined in (11). This controller is continous and does not need computation of the equivalent control which is quite common in many SMC based control approaches.

$$
\begin{aligned}
& \dot{x}=f(x)+B(x) u \\
& u(k)=u(k-1)-(G B)^{-1}(\dot{\sigma}(k-1)+D \sigma(k-1)) \\
& \sigma=\left(\dot{x}_{r e f}-\dot{x}\right)+C\left(x_{r e f}-x\right)
\end{aligned}
$$

where $G=\frac{d \sigma}{d x}$.

Controller is implemented for both MAF and MAP channels where disturbance observer is utilized only for EGR inner loop. Simulation results for step tests with and without disturbances are presented in the following section.

\section{RESUlts}

Controller performance evaluation is done via acceleration pedal position steps (load step). MAF setpoints are interpolated from desired value maps and they are limited with maximum possible flow to create feasible setpoints. In this maneuver, good tracking behaviour is achieved when there is no external disturbance (Fig. 6) .

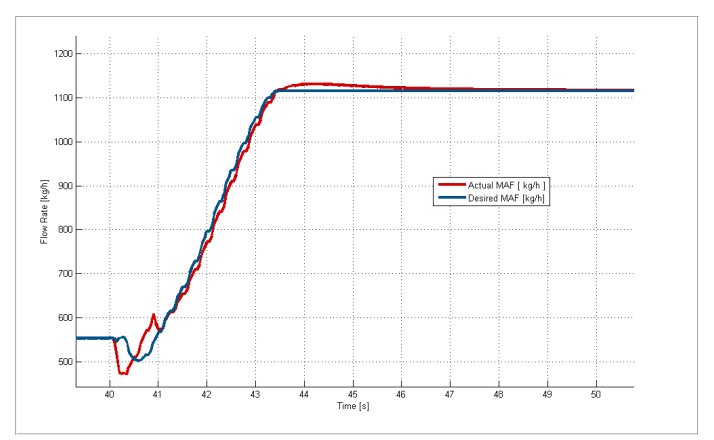

Fig. 6. MAF control result for $20 \%$ to $80 \%$ load step test

External disturbances in the form of sinusoidal and pulse waveforms are then applied to the EGR valve positon and the system is simulated.

Applied disturbances and their estimated values by DOB are presented in the Fig. 7 and 8. DOB output may include any real plant behaviour that can not be captured by the nominal inverse plant. It should be noted that only disturbances that are in the bandwith of the low-pass filter can reliably be estimated. It can be observed from these figures that while sinusoidal disturbance waveform is preserved with only a slight phase shift in the estimation, pulse disturbance is estimated with some significant deterioration in the waveform. However, for both type of disturbances simulation results provided in Fig. 9-12 showed that using DOB improves the performance of the system. Since the outer loop is also robust controller system has disturbance rejection capability without

(8) DOB to certain extend. 


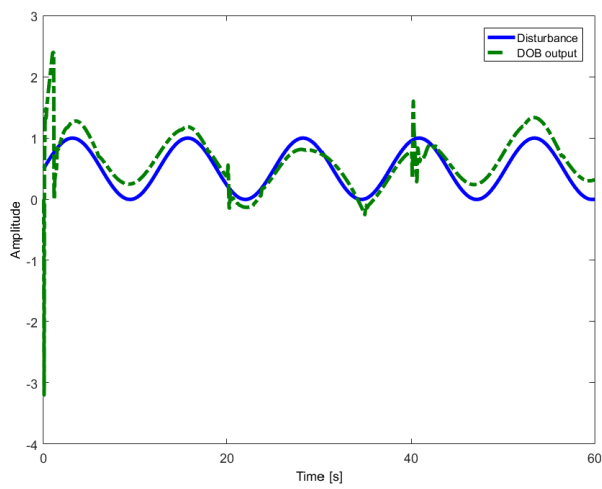

Fig. 7. Sinusoidal disturbance vs. DOB output

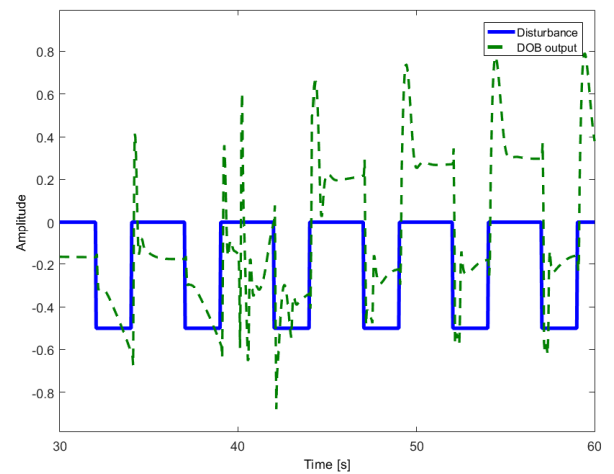

Fig. 8. Pulse array disturbance vs. DOB output

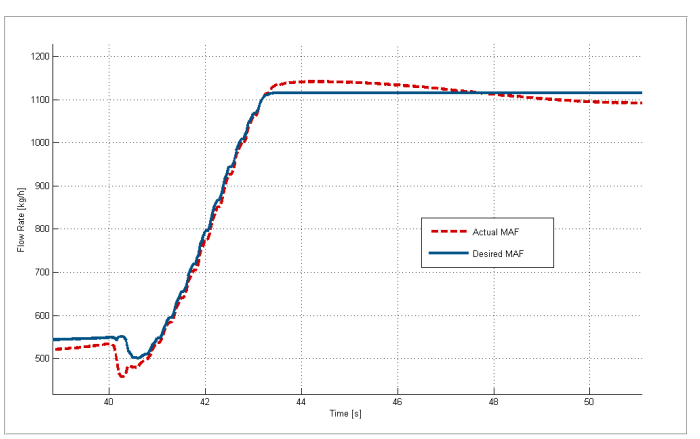

Fig. 9. The step test - sinusoidal disturbance and DOB inactive

\section{CONClusions ANd Future Works}

For diesel engines, valve behaviours are differing with aging and production tolerances. Capturing the actuator behaviour changes is important for total fleet performance. A data driven disturbance observer (DOB) design with discrete time sliding mode control (DTSMC) for outer loop is proposed and simulated on a heavy duty engine model. Results showed that DOB integrated DTSMC scheme provides far better disturbance rejection capability with increased tracking performance.

Continous time stability and bandwith issues for robust control systems hat utilize DOB are investigated in the liter-

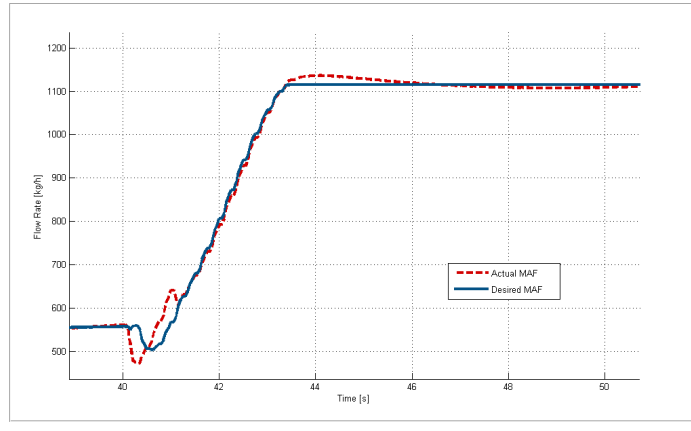

Fig. 10. The step test - sinusoidal disturbance and DOB active

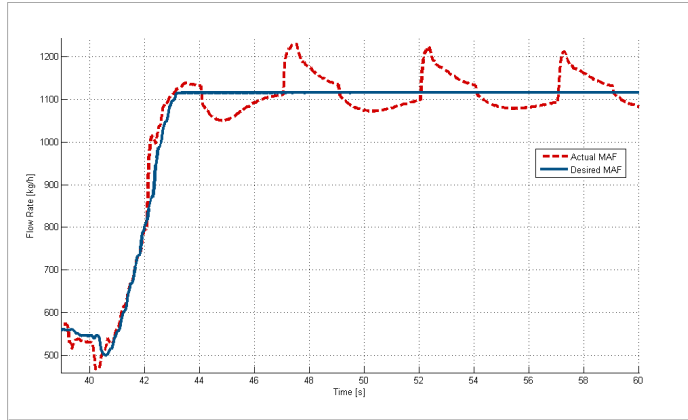

Fig. 11. The step test - pulse disturbance and DOB inactive

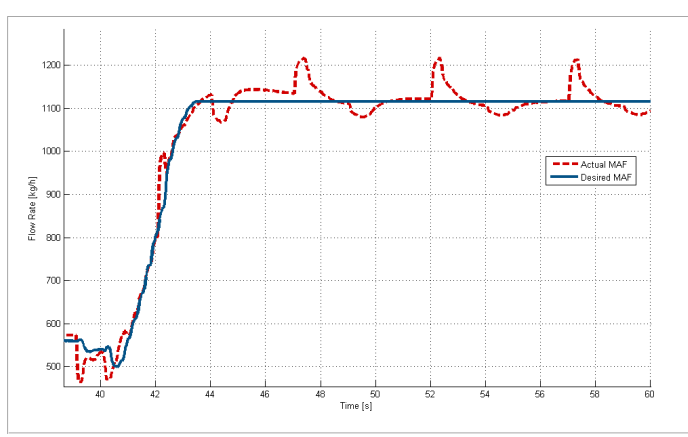

Fig. 12. The step test - pulse disturbance and DOB active

ature [33]. Discrete time stability analysis for the proposed DOB integrated DTSMC approach will be a future work where bandwith issues will also be addressed. For higher overall system performance, more effective data driven models for inverse nominal plant will also be investigated.

\section{ACKNOWLEDGEMENT}

The authors would like to thank Ford Otosan Powertrain Control Software team for their support on the plant model.

\section{REFERENCES}

[1] Heywood, J. Internal Combustion Engine Fundamentals McGraw-Hill Book Co. 2000

[2] M. J. Van Nieuwstadt, I. V. Kolmanovsky, P. E. Moraal, A. Stefanopoulou, and M. Jankovic, EGR-VGT control schemes: experimental comparison for a high-speed diesel engine, Control Syst. IEEE, vol. 20 , no. 3,2000 . 
[3] G. Stefanopoulou, I. Kolmanovsky, and J. S. Freudenberg, Control of variable geometry turbocharged diesel engines for reduced emissions, Proc. 1998 Am. Control Conf. ACC IEEE Cat No98CH36207, vol. 3, no. 4 , pp. $733745,2000$.

[4] J. Wahlstrom, L. Eriksson, and L. Nielsen, EGR-VGT control and tuning for pumping work minimization and emission control, IEEE Trans. Control Syst. Technol., vol. 18, no. 4, pp. 9931003, 2010.

[5] S. Formentin, S. M. Savaresi, and L. Del Re, Non-iterative direct data-driven controller tuning for multivariable systems: theory and application, IET Control Theory Appl., vol. 6, no. 9, p. 1250, 2012.

[6] P. Ortner and L. del Re, Predictive Control of a Diesel Engine airpath, Control Syst. Technol. IEEE Trans., vol. 15, no. 3, pp. 449456, 2007.

[7] H. J. Ferreau, P. Ortner, P. Langthaler, L. Del Re, and M. Diehl, Predictive control of a real-world Diesel engine using an extended online active set strategy, Annu. Rev. Control, vol. 31, no. 2, pp. 293301, 2007.

[8] G. Stewart and F. Borrelli, A model predictive control framework for industrial turbodiesel engine control, 2008 47th IEEE Conf. Decis. Control, pp. 57045711, 2008.

[9] T. Maruyama, T. Shimura, A. Ejiri, Y. Ikai, and K. Shimotani, Model Predictive Control Applied to a Diesel Engine Air-Path System with Dead Time, no. 2, pp. 26282633, 2011.

[10] J. Wahlstrom and L. Eriksson, Output selection and its implications for MPC of EGR and VGT in diesel engines, IEEE Trans. Control Syst. Technol., vol. 21, no. 3, pp. 932940, 2013

[11] A. Murilo, M. Alamir, and D. Alberer, A General NMPC Framework for a Diesel Engine airpath, Int. J. Control, no. June 2015, pp. 121, 2014.

[12] M. Huang, Robust Rate-Based Model Predictive Control of Diesel Engine airpath, pp. 15051510, 2014

[13] V. I. Utkin, H.-C. Chang, I. Kolmanovsky, and J. a Cook, Sliding Mode Control, in American Control Conference (ACC), 2000, 2000, no. June, pp. 584588.

[14] D. Upadhyay, Multivariable Control Design for Intake Flow Regulation of a Diesel, IFAC Proceedings Volumes Volume 35, Issue 1, 2002, Pages 277-282

[15] J. Wang, Hybrid robust air-path control for diesel engines operating conventional and low temperature combustion modes, IEEE Trans. Control Syst. Technol., vol. 16, no. 6, pp. 11381151, 2008.

[16] S. A. Ali and N. Langlois, Sliding mode control for diesel engine airpath subject to matched and unmatched disturbances using extended state observer, Math. Probl. Eng., vol. 2013, pp. 1013, 2013.

[17] M. Jung and K. Glover, Calibratable linear parameter-varying control of a turbocharged diesel engine, IEEE Trans. Control Syst. Technol., vol. 14, no. 1, pp. 4562, 2006.

[18] A. Amstutz and L. K. Del Re, EGO Sensor Based Robust Output Control, IEEE Trans. Control Syst. Technol., vol. 3, no. 1, pp. 3948, 1995.

[19] A. Plianos and R. K. Stobart, Nonlinear airpath control of modern diesel powertrains: a fuzzy systems approach, Int. J. Syst. Sci., vol. 42, no. 2, pp. $263275,2011$.

[20] M. Jankovic and I. Kolmanovsky, Robust nonlinear controller for turbocharged diesel engines, Am. Control Conf. , pp. 13891394, 1998.

[21] A. Sabanovic, K. Ohnishi Motion Control Systems IEEE Press 2011

[22] Z. S. Hou and Z. Wang, From model-based control to data-driven control: Survey, classification and perspective, Inf. Sci. (Ny)., vol. 235, 2013.

[23] A. Sabanovic, N. Sabanovic,K. Jezernik, Sliding Modes in Sampleddata Systems, Design, vol. 44, pp. 163181, 2003.

[24] B. Unver, Y. Koyuncuoglu, M. Gokasan, and S. Bogosyan, Modeling and validation of turbocharged diesel engine airpath and combustion systems, Int. J. Automot. Technol., vol. 17, no. 1, pp. 1334, Feb. 2016.

[25] M. Jung, K. Glover, and U. Christen, Comparison of uncertainty parameterisations for $\mathrm{H}$ infinity robust control of turbocharged diesel engines, Control Eng. Pract., vol. 13, no. 1, pp. 1525, 2005.

[26] P. Carlsson, Flow Through a Throttle Body : A Comparative Study of Heat Transfer, Wall Surface Roughness and Discharge Coefficient, p. 53, 2007.

[27] T. Boz, M. Unel, V. Aran, M. Yilmaz, C. Gurel, C. Bayburtlu, K. Koprubasi,Diesel Engine NOx Emission Modeling with Airpath Input Channels, 41st Annual Conference of the IEEE Industrial Electronics Society (IECON 2015), Yokohama, November 9-12, 2015.

[28] I. Kolmanovsky, Issues in modelling and control of intake flow in variable geometry turbocharged engines, Proc. 18th IFIP Conf. Syst. Model. Optim., pp. 436445, 1997.
[29] MATLAB and System Identification Toolbox Release 2013a, The MathWorks, Inc., Natick, Massachusetts, United States.

[30] Ohishi, K., Ohnishi, K., and Miyachi, K., 1983, Torque-Speed Regulation of dc Motor Based on Load Torque Estimation, Proc. IEEJ IPEC-TOKYO, 2, pp. 12091216.

[31] Z. Hongdong, Z. Guanghui, and S. Huihe, Control of the process with inverse response and dead-time based on disturbance observer, Am. Control Conf., pp. 48264831, 2005.

[32] Lennart Ljung, System Identification Toolbox User's Guide, MATLAB and System Identification Toolbox Release 2013a, The MathWorks, Inc., Natick, Massachusetts, United States.

[33] E. Sariyildiz and K. Ohnishi, A Guide to design disturbance observer, J. Dyn. Syst. Meas. Control, vol. 136, no. 2, p. 21011, 2013. 